\title{
Thoughts About Spinal Actions and Cerebral Reflections in Movement
}

\author{
G. M. Pool, MD \\ Oostdijkseweg 14a, Goedereede, Holland.
}

\begin{abstract}
Summary
Some thoughts about the co-ordination in movement are given and how our communication organ may be able to adapt to the disaster of an interruption in the information chain.
\end{abstract}

Key words: Polysynaptic transmission; Communication organ; Mental adjustment .

For the occasion of the first meeting of the International Medical Society of Paraplegia in the Southern hemisphere I would like to attract your attention to two quite different themes.

The first is the fortuitous discovery on the west coast of Australia by the crew of the ship 'De Eendracht' under command of Dirck Hartog in 1616. On the globe logo of 'Paraplegia' the route Dirck Hartog covered can be followed over and under the wheel of the wheelchair.

The second is the question of what might happen to our organ of communication in the event of a complete or partial block in the information chain; something which may occur gradually or suddenly, as in the case of paraplegia. Both themes have in common an unexpected destination.

A journey like that of the ship 'De Eendracht' can only be undertaken by a ship's crew and a commander who are splendidly co-ordinated and by men who are in possession of a splendid co-ordination of their entire central nervous system, which I like to call communication organ transmitting all the information of the outside world including that of human relations.

The course of a sailing ship amongst waves, stars, birds and streams with few navigational instruments other than the compass, depends on information obtained from memory, experience and of course muscle action to hoist the sails, direct the helm and so on.

Signals for movement are sent from the brain to our entire body through our communication organ and by way of reflex co-ordination a maximum result can be obtained with a minimum of energy. 
Figure 1 The flexion response.

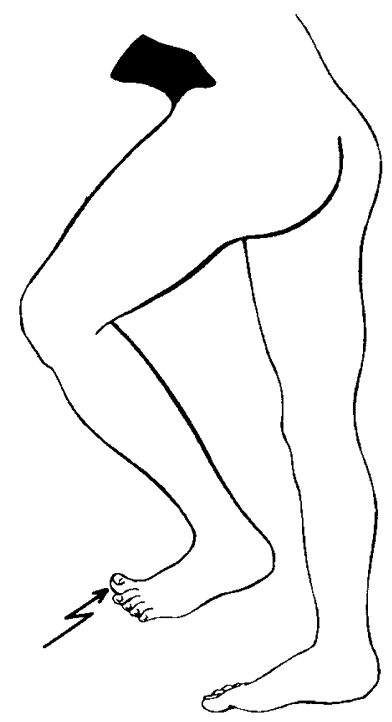

\section{Cord refiex actions}

The newborn already show a wonderful co-ordination of reflexes in movement actions as Professor Andre-Thomas has shown in his work with newborn babies, and as is well known from the study of other animals.

The Russian physiologist Bernstein in his book 'The Co-ordination and Regulation of Movements' states that economy of movement develops slowly as a result of experiment and exercise. According to him, locomotor acts belong to the category of extremely ancient movements. They are phylogenetically older than the cortical hemispheres and have undoubtedly affected the development of the central nervous system. Probably the oldest illustration of the brain and the cord is from the School of Alexandria ( \pm 1000 AD) and kept in Cambridge (Schulte, 1980).

It shows the brain around the skull, and also around the nine vertebrae there is nervous tissue. At that time it was already understood that the brain and the cord belong together although different in location and as we now know, different too in reflex action. The difference between the two lies in the predictability of their reaction: the cord reflex action is predictable, mono- or polysynaptic, whilst the cerebral reflexion is unpredictable and always polysynaptic. Both are reactions of the same organ and both influence each other.

In 1965 we published the myographic answers obtained after a moving or noxious electrical stimulus was applied to the sole of the foot or beneath the skin of the sole of the foot. The myographic pattern in the rectus femoris part of the quadriceps had three different forms. In more than 100 examinations we never saw a movement which differed from withdrawal from the stimulus, the so-called flexion response. We never saw a movement of the arm, the trunk or the face, but just the same well known polysynaptic reflex flexion response (Fig. 1). 


\section{Cerebral reflections}

In contrast with the one and only polysynaptic response of the lower limb, the number of polysynaptic connections in the brain are manifold and much more complex. In his book 'The Understanding of the Brain', Sir John Eccles shows in a scheme how a combined tactile and visual recognition of an object is thought.

Experimental evidence for the immense influence of sensory inputs is provided by the electroencephalogram: the afferent input by a touch on the skin may greatly disturb the alpha rhythm as does opening of the eyes.

The influence of touch and vision should be looked upon as influences of the environment on our communication organ, just as in the case of stimulating the sole of the foot, which elicites the flexion reflex in walking!

But what happens if information from the environment is lost as is the case in paraplegia? Is our communication organ able to adapt to that situation and how long does it take?

\section{Mental adjustment}

Sir Ludwig Guttmann has already dealt with this problem. In the last chapter of his book he wrote: 'It is obvious that the essence of rehabilitation must lie in restoring activity of mind' and he attempted to analyse the nature of talent.

Sir John Eccles concluded that the nervous system is not working in some unitary and dictatorial manner.

This is on the basis of the work of Jones and Powell who have shown that the primary sensory area in the cortex projects in an orderly manner to a multitude of circumscribed zones not only in the parietal lobe but also in the temporal, frontal and limbic lobes. Their demonstration provides the anatomical substrate for cross-modal interaction, such as confluence of tactile and visual inputs.

These findings are matched by physiological investigations on the somatosensory system by many others; and this perhaps is how patients can adapt to the change in information inflow, the adaptation of the cerebral part of our communication organ and the system gradually restores its balance.

I presume that adaptations is what Kerr and Thomson prefer to call mental adjustment. They concluded that mental adjustment is a gradual process that takes at least 2 years to stabilise.

During that period the patient needs all the help that he can get to develop his mental powers.

\section{The role of the paraplegist as a leader}

Turning to the role of the paraplegist I like to quote Bedbrook and Jousse. Bedbrook states: 'Adequate clinical judgement needs physicians who have knowledge of morbid pathology, physiology and human understanding'; Jousse asks for ongoing encouragement and support by a trusted medical attendant.

A paraplegist should be a sheep with five legs. He must understand the syndrome and should be aware of his place as a link between the patient and the outside world. (Fig. 2). But most important of all, he must be able to steer his 


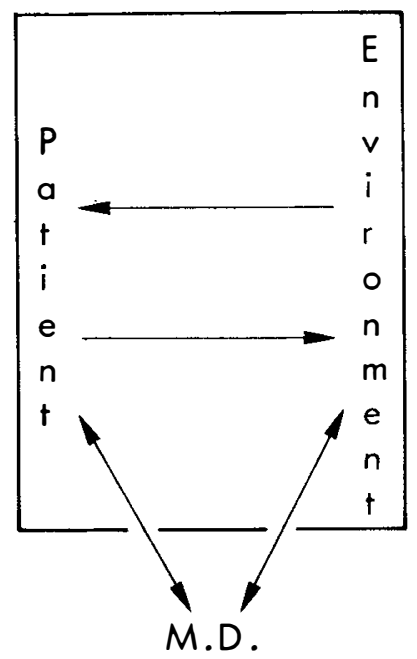

Figure 2 The doctor as a link between the patient and the outside world.

patient with a badly damaged communication organ through difficult waters on an uncertain voyage to a new destination with a renewed balance.

In 1616 on board his ship 'De Eendracht' Dirck Hartog who displayed the qualities of a real master, pointed out a new direction to his crew when they had lost their way on an unknown coast. Realising that this landfall may have been a major discovery the crew left a pewter plate behind to commemorate their stay in Hollandia Nova. Eighty one years later that plate was found by another Dutch commander, Captain De Vlaming, when he happened to be in those waters. De Vlaming replaced Den Hartog's plate by one of his own, which is now in the Maritime Museum in Freemantle. (Den Hartog's plate itself is in the Rijksmuseum in Amsterdam).

From 1980-1984 an Australian master showed the way which the International Medical Society should follow to a new balance of power.

To commemorate his leadership I have brought a new pewter plate from Holland, which I hope Sir George Bedbrook will accept from a modern day De Vlaming! (Fig. 3). 


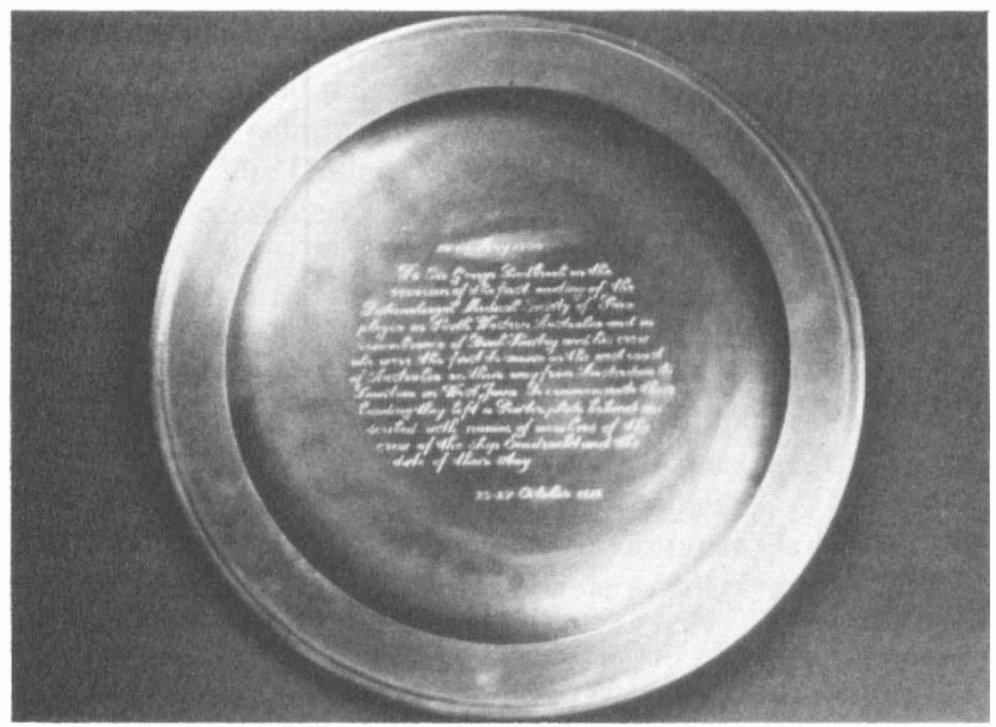

Figure 3 The pewter plate presented to Sir George Bedbrook. 10-12 May 1988. To Sir George Bedbrook on the occasion of the first meeting of the International Medical Society of Paraplegia in Perth, Western Australia and in remembrance of Dirck Hartog and his crew who were the first to arrive on the west coast of Australia on their way from Amsterdam to Bantum in west Java. To commemerate their landing they left a pewter plate behind inscribed with the names of members of the crew of the ship Eendracht and the date of their stay: 25-27 October 1616.

\section{References}

Thomas, A, AUtergaerden S 1966 Locomotion from pre- to post-natal life. Clinics in development medecin No 42. Heinemann, London.

BEDBROOK GM 1966 Pathological principles in the management of spinal cord trauma. Paraplegia 4: 43-56.

BERNSTEIN N 1967 The co-ordination and regulation of movements. Pergamon Press, pp 104113.

ECCLES JC 1977 The understanding of the brain. McGraw-Hill Book company.

GutTMANN L 1973 Spinal cord injuries-comprehensive management and research. Blackwell Scientific Publications, pp 639-645.

JONES EG, POWELL TPS 1970 An anatomical study of converging sensory pathways within the cerebral cortex of the monkey. Brain 93: 793-820.

JouSSE AT 1982 Late complications of traumatic paraplegia. Editorial. Paraplegia 20: 18-19. KERR WG, ThOMSON MA 1972 Acceptance of disability of sudden onset in paraplegia. Paraplegia 10: 94-102.

Pool GM 1965 Electro-myographic study of the flexion reflex of the lower limb. Paraplegia 3: 188-193.

Pool GM 1966 Flexion reflex and stretch reflex in spasticity. Paraplegia 4: 141-146.

SCHILDER G 1976 Australia unfailed. Theatrum Orbis Terrarum, Amsterdam.

SCHULTE BPM 1980 Het bezien van de Menselÿke hersenen. Hofmann-La Roche Mijdrecht, pp 15-16. 